\title{
不同生境间红树科植物水分利用效率的比较研究
}

\author{
黄建辉 林光辉 韩兴国 \\ (中国科学院植物研究所植被数量生态学重点实验室, 北京 100093)
}

\begin{abstract}
摘 要 通过测定采自 4 个地区 (海南、厦门、北海和西双版纳) 的红树科 6 个属共 9 种植物, 包括竹节树 (Carallia brachiata)、锯叶竹节树 ( C. diphopetala)、山红树 ( Pellacalyx yunnanensis)、红树 ( Rhizophora apiculata)、红海榄 ( R. stylosa)、海莲 (Bruguiera sexangula)、木览 ( B. gymnorhiza)、秋茄 (Kandelia candel) 和角果木 (Ceriops tagal) 的叶片碳同位素 比值 $\left({ }^{13} \mathrm{C}\right.$ ), 比较了不同地区分布的红树科植物 (尤其是内陆生长的和沿海生长的红树科植物之间)、同一地区分 布不同种红树科植物间以及不同季节红树科植物 ${ }^{13} \mathrm{C}$ 值及其所反映的胞间 $\mathrm{CO}_{2}$ 浓度和水分利用效率的差异。研 究结果表明, 红树科植物叶片的 $\delta{ }^{13} \mathrm{C}$ 变化在 $-32 \% 0 \sim-26 \%$ 之间, 大部分种类在两个生长季之间(春季和秋季)没 有明显的差异, 而内陆和沿海分布的红树科植物有着显著不同的 $\delta{ }^{13} \mathrm{C}$ 值, 以海水中生长的红树科植物 $\delta{ }^{13} \mathrm{C}$ 值较 高。此外, 在海水中生长的红树科植物以北海地区分布的为最高, 而在厦门和海南之间则较少有显著性的差异。 从所取得的结果来看, 植物 ${ }^{13} \mathrm{C}$ 值之间的差异可能有遗传学的基础, 但环境的影响也起很大的作用。
\end{abstract}

关键词 红树植物 $\delta{ }^{13} \mathrm{C}$ 值 水分利用效率

\section{COMPARATIVE STUDIES ON WATER USE EFFICIENCY OF RHIZOPHORACEAE PLANTS GROWN IN DIFFERENT ENVIRONMENTS}

\author{
HUANG Jian-Hui LIN Guang-Hui and HAN Xing-Guo \\ (Laboratory for Quantitative Vegetation Ecology, Institute of Botany, Chinese Academy of Sciences, Beijing 100093, China)
}

\begin{abstract}
We determined the $\delta{ }^{13} \mathrm{C}$ values of leaf samples collected from plants belonging to 6 genera in the Rhizophoraceae family grown in four locations in China, including three coastal areas (Dongzhaigang of Hainan Province, Xiamen of Fujian Province, Beihai of Guangxi Zhuang Autonomous Region), and one inland area (Xishuangbanna of Yunan Province) in May and September, 2002. The nine plant species included Carallia brachiata, C. diphopetala, Pellacalyx yunnanensis, Rhizophora apiculata, R. stylosa, Bruguiera sexangula, B. gymnorhiza, Kandelia candel, and Ceriops tagal. The results indicated that leaf $\delta{ }^{13} \mathrm{C}$ values, corresponding to integrated wateruse efficiency ( $W U E$ ) (ratio of $\mathrm{CO}_{2}$ assimilation rate to leaf transpiration), ranged from $-32 \%$ to $-26 \%$, but did not vary significantly between May and September in most of those plant species. However, there were significant differences in leaf $\delta{ }^{13} \mathrm{C}$ values among growing environments with lower foliar $\delta{ }^{13} \mathrm{C}$ values for the plants grown in the inland than those in the coastal areas on two sampling dates, indicating a higher intercellular $\mathrm{CO}_{2}$ concentration and thus a lower water use efficiency for the plants grown in the inland. In addition, among those plants living in the coastal areas, the leaves of plants grown in the Beihai had the highest $\delta{ }^{13} \mathrm{C}$ values indicating the lowest intercellular $\mathrm{CO}_{2}$ concentration and thus highest WUE, which may be caused by the high salt content in the seawater or high water stress in Beihai. Our results suggest that the foliar $\delta{ }^{13} \mathrm{C}$ values of the plants in the Rhizophoraceae family could be highly affected by intermittent environmental factors, although their genetic characteristics may play a significant role in determining their foliar $\delta{ }^{13} \mathrm{C}$ values.
\end{abstract}

Key words Rhizophoraceae, $\delta{ }^{13} \mathrm{C}$ values, Water use efficiency

红树科植物约有 16 属 120 余种, 主要分布于热 带地区。我国有 6 属 13 种 1 变种。该科可分为 3 个族, 我国有 2 个族, 即竹节树族 (Trib. Legnotideae
Benth. et Hook.) 和红树族( Trib. Rhizophoreae Benth. et Hook.)。前者在我国共有 2 属 5 种, 主要分布于 云南、广西等地的内陆或山地, 是组成热带、亚热带 
森林群落的非优势树种; 后者则包含了 4 属 8 种, 主 要分布于我国的广东、广西、海南、福建、台湾等地的 浅海盐滩, 是组成红树林 (Mangrove) 的主要植物种 类(高蕴璋, 1983)。红树林是热带和亚热带沿海地 区特有的植物群落, 在我国主要分布于南方海边。 构成红树群落的植物, 虽然以红树科植物为主, 但其 它科属尚在形态上和生态上具有此群落特点的植物 亦统属之。

与生长在热带雨林的同科植物相比, 生长于海 水中的红树科植物, 如红树 (Rhizophora apiculata)、红 海榄( R. stylosa) 、海莲 (Bruguiera sexangula)、木榄 ( B. gymnorrhiza)、秋茄 (Kandelia candel) 和角果木 (Ceriops tagal) 等, 除了要克服水淹引起氧气不足的 不利因素外,还需要克服海水中因高盐含量所造成 的逆境条件。一般来说, 红树植物所生长的环境中 盐分含量通常介于淡水和海水之间, 前者的盐度接 近零，后者的盐度通常在 $35 \%$ 左右。海水的渗透势 在 $-2.5 \mathrm{Mpa}$ 左右, 红树植物必须克服这一阻力才 能吸收到维持其生命的水分。海水中高的盐分含量 使分布于这种环境中的植物面临 3 个方面的问题: 1)外界溶液渗透压可能超过植物细胞的, 从而需要 调节, 以避免过分脱水;2) 养分离子如 $\mathrm{K}$ 和 $\mathrm{Ca}$ 的吸 收和传递会被过量的 $\mathrm{Na}$ 离子打断; 3$) \mathrm{Na}$ 和 $\mathrm{Cl}$ 离子 对细胞膜和酶系统有直接的毒害作用 (Glenn et al., 1997）。高盐分含量对红树植物叶片的光合作用至 少有两个方面的潜在限制, 即高的叶片水分亏损和 低的气孔导度 (Ball \& Farquhar, 1984; Björkman et $a l ., 1988)$ 。事实上,海水中盐分的含量往往会因为 降雨和温度的季节性变化儿出现波动。降雨使得海 水盐度降低,而温度升高导致水分蒸发增加而引起 海水中盐度的增加。因此, 局部的高温蒸发可能使 得海水的盐度提高到原来的 2 倍, 从而使得红树植 物的生存条件变得更为严峻 (Hogarth, 1999)。

虽然红树植物生长在一个经常淹水的环境中, 但水分对它们的生长却是一个限制因子, 即红树植 物的生长除了受到氧气供给的限制和高盐分以外, 还受到了来自因高盐分而造成的水分胁迫 (Ball, 1988）。因此,水分来源和有效性是影响红树植物分 布和生长的一个重要因素。海水中的高盐分造成了 实际上的水分缺乏, 导致生长于该环境的红树植物 叶片的气孔导度降低, 叶片的胞间 $\mathrm{CO}_{2}$ 浓度降低, 提 高了水分利用效率 (Ball \& Farquhar, 1984; Clough \& $\mathrm{Sim}$, 1989)。由于叶片的胞间 $\mathrm{CO}_{2}$ 较低, 红树植物在 进行光合作用时利用较多的 ${ }^{13} \mathrm{CO}_{2}$, 导致了较高的 $\delta{ }^{13} \mathrm{C}$ 值 ( Lin \& Sternberg, 1992)。因此, 红树植物叶片 的 $\delta{ }^{13} \mathrm{C}$ 值的高低能反映出叶片的水分亏缺状况、 胞间 $\mathrm{CO}_{2}$ 浓度的高低以及水分利用效率 (Ehleringer et al., 1986, 1987; Clough \& Sim, 1989; Huc et al., 1994; Lloyd \& Farquhar, 1994)。

本文拟通过对生长在不同地区和生境的红树科 植物叶片中 ${ }^{13} \mathrm{C}$ 自然丰度的测定, 比较: 1) 不同地区 生长的同种红树科植物; 2) 同一地区生长的不同种 类红树科植物; 3 ) 海水和淡水生长红树科植物间水 分利用效率的差异, 以探讨生境条件和遗传因子对 红树科植物生理生态特征的影响。

\section{1 材料和方法}

\section{1 研究地点}

所采集的红树科植物样品中, 秋茄是较为广布 的一种, 分布在海南、香港、澳门、广东、广西、台湾、 福建、浙江等地，木榄分布在海南、香港、广东、广西、 台湾、福建等地, 角果木分布于海南、广东和台湾, 红 海榄分布于海南、广东和广西, 而红树和海莲则仅分 布于海南 (范航清, 2001)。竹节树 (Carallia brachia$t a$ )在我国主要分布于福建、广东、海南、香港、广西 和云南, 锯叶竹节树 ( $C$. diphopetala) 主要分布于广 西和云南, 而山红树 (Pellacalyx yunnanensis) 则主要 分布于云南(覃海宁, 2001)。上述 9 个种分别属于 6 个属, 其中淡水生长的 3 种, 海水生长的 6 种。

福建(厦门): 5 月主要采集了两种红树科植物: 秋茄和木榄, 采集地为龙海市浮宫镇 (位于 $24^{\circ} 24^{\prime} \mathrm{N}$, $117^{\circ} 23^{\prime}$ E) 红树林自然保护区的九龙江口,9 月则增 加了红海榄。这几个种在浮宫均分布于秋茄、白骨 壤( Avicennia marina) 群落上侧。该采集地属南亚热 带气候, 年均气温 $21^{\circ} \mathrm{C}$, 年均降水量 $1365.1 \mathrm{~mm}$, 年 均相对湿度 $81 \%$, 土壤含盐量为 $15 \%$ 21\%o, $\mathrm{pH}$ 接 近 7, 海水总盐度为 17.1 (赵可夫等, 1999)。

广西(北海): 采集地位于广西北海大冠沙(位于 $21^{\circ} 26^{\prime} \mathrm{N}, 109^{\circ} 14^{\prime} \mathrm{E}$ ), 所采集的秋茄和红海榄也零星 分布于白骨壤群落中。该地区年平均温度为 $22.4{ }^{\circ} \mathrm{C}$, 极端最低温为 $0.5{ }^{\circ} \mathrm{C}$, 年平均相对湿度为 $82 \%$, 潮汐为全日潮, 平均潮差为 $2.36 \mathrm{~m}$, 最大潮差 为 $5.36 \mathrm{~m}$ 。林内土壤在部分岸段从内滩、中滩到外 滩依次为淤泥质、泥沙质和沙质,一些岸段以沙质土 壤为主 (梁士楚, 2001)。

海南: 主要采集了秋茄、红海榄、红树、海莲、角 果木、木榄等植物, 采集地在琼山县的东寨港 (位于 $19^{\circ} 51^{\prime} \mathrm{N}, 110^{\circ} 24^{\prime} \mathrm{E}$ ) 红树林自然保护区。该地区属 
北热带海洋气候, 年平均气温为 $23.7^{\circ} \mathrm{C}$, 最冷月平 均气温为 $17.3{ }^{\circ} \mathrm{C}$, 年平均降雨量 $1942 \mathrm{~mm}$ ( 叶勇等, 2000)。

西双版纳: 主要采集了竹节树、锯叶竹节树和山 红树。采样地位于西双版纳预仑镇的葫芦岛 (位于 $21^{\circ} 54^{\prime} \mathrm{N}, 101^{\circ} 46^{\prime} \mathrm{E}$ )。该地区属西南季风气候, 海拔 高度 $560 \mathrm{~m}$, 一年可分为干热、湿热及雾凉 3 季, $3 \sim 5$ 月为干热季, 气温较高, 降雨量少; 6 10 月为雨季, 气候湿热, 全年 $85 \%$ 的雨水集中在此期间降落; 11 月～翌年 2 月为雾凉季, 降水量减少, 但早晚浓雾弥 漫, 空气湿度较大。年平均气温 $21.6{ }^{\circ} \mathrm{C}$, 最热月 ( 5 月)平均气温 $25.3{ }^{\circ} \mathrm{C}$, 最冷月 1 月平均气温 15.5 ${ }^{\circ} \mathrm{C}$, 平均年降雨量为 $1557.0 \mathrm{~mm}$, 年平均相对湿度 $86 \%$, 年日照时数 $1828.0 \mathrm{~h}$, 有雾日数 $173.7 \mathrm{~d}$ (唐建 维等,2003)。

\section{2 样品采集和处理}

选择健康、正常生长的植株, 采集 3 5 片无破 损的成熟叶片。每个种采集 3 个植株, 为 3 个重复。 将所采集的叶片样品置于常规的干燥箱中, 于 $70{ }^{\circ} \mathrm{C}$ 条件下烘 $48 \mathrm{~h}$ 。然后粉碎, 过 20 目篮。

\section{3 稳定性同位素分析}

碳同位素比率采用 Manchaster 的 Fison 公司生 产的 Isochroam 连续流动同位素比例质谱仪分析, 由 美国哥伦比亚大学生物圈 2 号稳定性同位素实验室 完成。碳同位素比率采用 $\delta{ }^{13} \mathrm{C}$ 的表达形式, 由下 式计算而得：

$$
{ }^{13} \mathrm{C}(\%)=\left(R_{\text {sample }} / R_{\text {standard }}-1\right) \times 1000
$$

式中, $R$ 为 ${ }^{13} \mathrm{C} /{ }^{12} \mathrm{C}$ 的比值, $R_{\text {sample }}$ 为测定样品的 $R$ 值, $R_{\text {standard }}$ 为标准物质的 $R$ 值, 标准物质采用国际 普遍认可的 PDB( Pee Dee Belminite)。

\section{4 数据分析}

数据分析采用 EXCEL 软件完成, 所有的统计分 析都是采用 SPSS 软件的 ANOVA 模块完成的。

\section{2 实验结果}

表 1 分别列出了 5 月和 9 月两个生长季节所采 集的红树植物叶片 $\delta{ }^{13} \mathrm{C}$ 值。本研究中所采集的红 树科不同种植物 $\delta{ }^{13} \mathrm{C}$ 值变化在 $-32.5 \%$ (西双版纳 的竹节树 ) - 26.9\% (北海的秋茄)之间。同一种 植物在 5 月和 9 月两个季节 ${ }^{13} \mathrm{C}$ 值的变化较为复 杂,并没有显示出任何规律性的特征。两个季节均 有采样的 9 个种中, 有 7 个种 $\delta{ }^{13} \mathrm{C}$ 值的变化显著 (图 1)。其中, 云南的山红树, 海南的秋茄和角果木 的 $\delta{ }^{13} \mathrm{C}$ 值降低, 而海南的海莲和木榄, 福建厦门的 木榄和秋茄则显著增加, 其变化幅度可以达到两个 千分单位以上。

从 5 月和 9 月不同地区典型红树科红树植物 $\delta^{13} \mathrm{C}$ 值的特征来看, 4 个地区的 10 种红树科红树植 物可以明显地分成 3 组, 即采自西双版纳的 3 种竹 节树族的植物, 其 $\delta{ }^{13} \mathrm{C}$ 值明显地低于红树族的植 物; 在红树族的植物中又根据分布地区的不同又可 以分成北海分布的红树植物和厦门、东寨港分布的

表 14 个采样地 2 次采样的红树科植物 $\delta{ }^{13} \mathrm{C}$ 值

Table 1 Foliar $\delta{ }^{13} \mathrm{C}$ values for the plants belonging to the Rhizophoraceae family grown in various locations of China

\begin{tabular}{|c|c|c|c|c|c|c|c|}
\hline \multirow{3}{*}{$\begin{array}{c}\text { 中文名 } \\
\text { Chinese name }\end{array}$} & \multirow{3}{*}{$\begin{array}{c}\text { 拉丁名 } \\
\text { Scientific name }\end{array}$} & \multirow{3}{*}{$\begin{array}{l}\text { 采样地 } \\
\text { Location }\end{array}$} & \multirow{3}{*}{$\begin{array}{c}\text { 纬度 } \\
\text { Latitude }\end{array}$} & \multicolumn{4}{|c|}{ 采样时间 Sampling time } \\
\hline & & & & \multicolumn{2}{|c|}{ 五月 May } & \multicolumn{2}{|c|}{ 九月 September } \\
\hline & & & & $\delta^{13} \mathrm{C}(\% o)$ & 标准误 $(S E)$ & $\delta{ }^{13} \mathrm{C}(\% \circ)$ & 标准误 $(S E)$ \\
\hline \multirow[t]{3}{*}{ 秋茄 } & Kandelia candel（KCF） & 福建 (F) & $24^{\circ} 24^{\prime} \mathrm{N}$ & $-28.4^{\mathrm{di}}$ & 0.3 & $-29.6^{\text {bilmn }}$ & 0.6 \\
\hline & Kandelia candel（KCG） & 广西 (G) & $21^{\circ} 26^{\prime} \mathrm{N}$ & $-26.1^{\mathrm{e}}$ & 0.1 & $-26.9^{\text {gik }}$ & 0.1 \\
\hline & Kandelia candel ( $\mathrm{KCH})$ & 海南 $(\mathrm{H})$ & $19^{\circ} 51^{\prime} \mathrm{N}$ & $-30.3^{\mathrm{ab}}$ & 0.4 & $-28.5^{\mathrm{fl}}$ & 0.2 \\
\hline \multirow[t]{3}{*}{ 红海榄 } & Rhizophora stylosa（RSF） & 福建 (F) & $24^{\circ} 24^{\prime} \mathrm{N}$ & - & - & $-28.1^{\mathrm{fk}}$ & 0.3 \\
\hline & Rhizophora stylosa（RSG） & 广西 (G) & $21^{\circ} 26^{\prime} \mathrm{N}$ & $-28.0^{\mathrm{d}}$ & 0.1 & $-27.3^{\mathrm{fi}}$ & 0.3 \\
\hline & Rhizophora stylosa（RSH） & 海南 (H) & $19^{\circ} 51^{\prime} \mathrm{N}$ & $-28.4^{\mathrm{df}}$ & 0.2 & $-27.9^{\mathrm{fj}}$ & 0.1 \\
\hline \multirow[t]{2}{*}{ 木榄 } & Bruguiera gymnorrhiza（BGF） & 福建 $(\mathrm{F})$ & $24^{\circ} 24^{\prime} \mathrm{N}$ & $-28.8^{d}$ & 0.3 & $-29.9^{\text {biln }}$ & 0.3 \\
\hline & Bruguiera gymnorrhiza (BGH) & 海南 (H) & $19^{\circ} 51^{\prime} \mathrm{N}$ & $-29.0^{\text {fghij }}$ & 0.3 & $-30.1^{\mathrm{abh}}$ & 0.4 \\
\hline 角果木 & Ceriops tagal ( CTH) & 海南 $(\mathrm{H})$ & $19^{\circ} 51^{\prime} \mathrm{N}$ & $-29.9^{c j}$ & 0.9 & $-27.6^{\mathrm{fg}}$ & 0.2 \\
\hline 红树 & Rhizophora apiculata（RAH） & 海南(H) & $19^{\circ} 51^{\prime} \mathrm{N}$ & $-28.6^{\mathrm{dg}}$ & 0.1 & $-28.4^{\mathrm{fm}}$ & 0.2 \\
\hline 海莲 & Bruguiera sexangula（BSH） & 海南 (H) & $19^{\circ} 51^{\prime} \mathrm{N}$ & $-28.0^{\mathrm{dh}}$ & 0.2 & $-30.5^{\mathrm{ab}}$ & 0.1 \\
\hline 山红树 & Pellacalyx yunnanensis (PYY) & 云南(Y) & $21^{\circ} 54^{\prime} \mathrm{N}$ & $-32.9^{b}$ & 0.4 & $-31.5^{\text {ade }}$ & 0.2 \\
\hline 竹节树 & Carallia brachiata (CBY) & 云南(Y) & $21^{\circ} 54^{\prime} \mathrm{N}$ & $-31.5^{\mathrm{a}}$ & 0.2 & $-32.5^{\mathrm{ce}}$ & 0.3 \\
\hline 锯叶竹节树 & Carallia diphopetala (CDY) & 云南(Y) & $21^{\circ} 54^{\prime} \mathrm{N}$ & $-32.8^{\mathrm{b}}$ & 0.3 & $-32.3^{\mathrm{cd}}$ & 0.4 \\
\hline
\end{tabular}

F: Fujian G: Guangxi H: Hainan Y: Yunnan 不同的字母表示差异显著 There is significant difference between $\delta{ }^{13} \mathrm{C}$ values with different leffers in the same column 


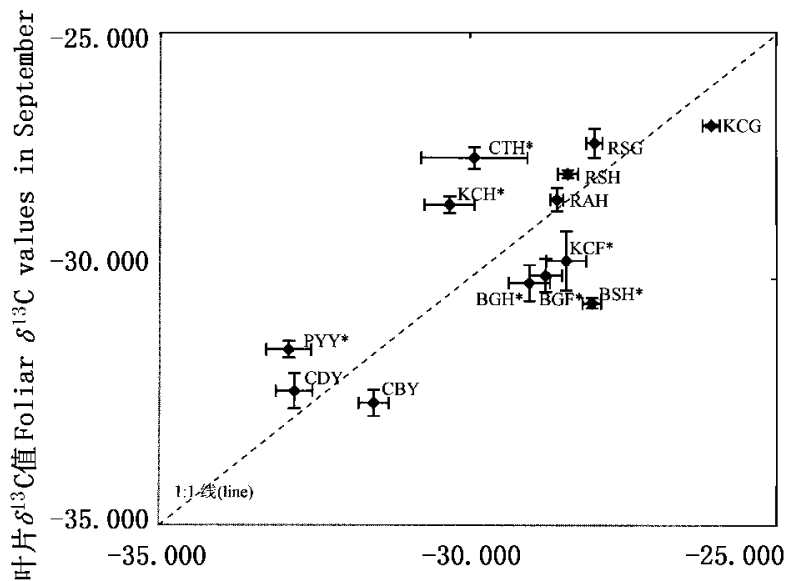

五月叶片 $\delta^{13} \mathrm{C}$ 值 Foliar $\delta^{13} \mathrm{C}$ values in May

图 1 红树科植物 5 月和 9 月 2 次采样 $\delta^{13} \mathrm{C}$ 值的比较

Fig. 1 Comparison in the foliar $\delta{ }^{13} \mathrm{C}$ values of Rhizophoraceae plants between 2 sampling dates, May and September

每一个点旁边的字母代表植物种类和采集位置 (见表 1) Characters beside each dot represent the name of a plant species ( see Table 1 for details）* 表示前后 2 次采样 $\delta{ }^{13} \mathrm{C}$ 值的变化显著 The symbol “*” denotes the significance found in $\delta{ }^{13} \mathrm{C}$ values of the same species at the same site between two sampling dates $(p<0.05)$ 每一个点上横向和纵向柱 为标准误 Horizontal and vertical bars at each point display standard errors of the mean $\delta{ }^{13} \mathrm{C}$ values of plant leaves 虚线 $(1: 1$ 线)表示同一个采样点 同一个种 2 次采样的 $\delta^{13} \mathrm{C}$ 值没有变化时点的位置 The dashed line (1:1 line) is the line expected if no change in $\delta{ }^{13} \mathrm{C}$ values at two sampling dates

红树植物, 其中北海分布的红树植物的 $\delta{ }^{13} \mathrm{C}$ 值显 著地高于另外两个地方的。而在厦门和东寨港分布 的大多数红树植物 $\delta{ }^{13} \mathrm{C}$ 值之间并没有显著的差 异。

\section{3 讨 论}

在光合作用的气体交换过程中, 植物所同化 $\mathrm{CO}_{2}$ 的稳定性同位素比率 $\left({ }^{13} \mathrm{C} /{ }^{12} \mathrm{C}\right)$ 同大气中的 $\mathrm{CO}_{2}$ 是有所不同的。导致这一差异的原因来自于气 体扩散过程中的分馏 (也称分差) (Diffusional fractionation) 和酶的分馏作用 (Enzymatic fractionation)。 另外, $\mathrm{CO}_{2}$ 在叶片中的融解过程也可能产生同位素 分馏效应。因此, 不同光合途径 $\left(C_{3} 、 C_{4}\right.$ 和 $\left.C A M\right)$ 因 光合羧化酶 (RuBP 和 PEP 羧化酶) 和发生羧化的时 间和空间上的差异对 ${ }^{13} \mathrm{C}$ 有不同的识别和排斥，导致 了不同光合途径的植物具有显著不同的 $\delta{ }^{13} \mathrm{C}$ 值。 研究表明, $\mathrm{C}_{3}$ 植物 $\delta{ }^{13} \mathrm{C}$ 值变化在 - 20\%o - 35\%。 (平均为 $-26 \%$ ), $\mathrm{C}_{4}$ 植物变化在 $-7 \% 0 \sim-15 \%$ (平 均为 $-12 \%$ ), 而 $\mathrm{CAM}$ 植物则差不多介于上述两类 植物之间，一般变化在 - 10\%o - 22\%o之间(平均为 $-16 \%$ ) ( O’ Leary, 1981)。从本研究中所采集的所有
红树科植物叶片 $\delta{ }^{13} \mathrm{C}$ 值来看, 这些植物属于典型 的 $\mathrm{C}_{3}$ 植物, 其 $\delta{ }^{13} \mathrm{C}$ 值变化在 $-32.5 \%$ (竹节树) $-26.9 \%$ ( 北海秋苏)之间。

但是, 植物 $\delta{ }^{13} \mathrm{C}$ 值不仅受植物光合途径 $\left(\mathrm{C}_{3} 、 \mathrm{C}_{4}\right.$ 和 CAM) 的影响, 而且还受一系列环境因子的影响。 研究表明, 光照、土壤水分、盐度、空气污染都有可能 引起植物 $\delta{ }^{13} \mathrm{C}$ 值显著的差异 (Farquhar et al., 1989)。但从总体上来说, 环境因子对植物 $\delta{ }^{13} \mathrm{C}$ 值 大小的影响要小于光合途径的。

叶片中有机物质的 $\delta{ }^{13} \mathrm{C}$ 值取决于扩散分差和 酶分差的相对影响, 进而取决于叶片胞间 $\mathrm{CO}_{2}$ 分压 $\left(C_{i}\right)$ 和大气 $\mathrm{CO}_{2}$ 分压 $\left(C_{a}\right)$ 。这一比率 $\left(C_{i} / C_{a}\right)$ 极为 重要, 因为它与植物的光合能力和气孔导度紧密相 关。这就是为什么叶片中的 $\delta^{13} \mathrm{C}$ 值可以用来衡量 植物的水分利用效率 (WUE) 的基本原理 (Farquhar et al.,1989)。当然, 仅有植物叶片的 $\delta{ }^{13} \mathrm{C}$ 值还不 能算出 $W U E$, 而只能作为 $W U E$ 的一个表征值 ( Indicative value)。在测得 $\delta{ }^{13} \mathrm{C}$ 值后, $\mathrm{C}_{3}$ 植物的 $W U E$ 可以通过下式可以计算:

$$
W U E=C_{a}\left[1-\left(\delta^{13} C_{a}-\delta{ }^{13} C_{p}\right) / \mathrm{a}(\mathrm{b}-\mathrm{a})\right] 1.6 \Delta W
$$
式中: $C_{a}$ 为大气 $\mathrm{CO}_{2}$ 浓度, $\delta{ }^{13} C_{a}$ 为大气 $\mathrm{CO}_{2}$ 碳同 位素比率, $\delta{ }^{13} C_{p}$ 为植物叶片碳同位素比率, $\mathrm{a}$ 为 $\mathrm{CO}_{2}$ 在空气扩散过程中的碳同位素分差 (4.4\%o), b 为 $\mathrm{RuBP}$ 羧化酶在同化 $\mathrm{CO}_{2}$ 过程中对 ${ }^{13} \mathrm{CO}_{2}$ 的判别 值 (Discrimination value， $\approx 27 \%$ ),$\Delta W$ 为叶片内外水 蒸汽压差( 可根据实验期间观测的大气温度和湿度 计算获得)(陈世苹等, 2002)。

3.1 同一种红树科植物在不同分布地区间水分利 用效率的差异

植物叶片的 $\delta{ }^{13} \mathrm{C}$ 值可能与不同地区的环境因 子的差别而产生差异, 如土壤中的一些养分的含量 引起同一种植物不同种群的个体间水分利用效率的 显著差异(Kao \& Chang，1998)。5 月在广西北海、福 建厦门和海南东寨港 3 地所采集的红树植物秋茄个 体间水分利用效率均有显著的差异 $(p<0.001)$, 其 中, 北海分布的秋茄具有最高的水分利用效率, 其表 征值 $\delta{ }^{13} \mathrm{C}$ 为 $-26.1 \%$; 其次是厦门的秋茄, $\delta{ }^{13} \mathrm{C}$ 为 $-28.4 \%$; 东寨港分布的秋茄具有最低的水分利用 效率, $\delta{ }^{13} \mathrm{C}$ 仅为 $-30.3 \%$ 。9 月, 情形有所不同, 水 分利用效率最高的仍为生长在北海的秋茄, 其 $\delta{ }^{13} \mathrm{C}$ 为 $-26.9 \%$, 显著高于东寨港和厦门生长的, 分别为 $-28.5 \%$ 和 $-29.6 \%$ ( $p=0.020$ 和 $p=0.000)$ 。同 时, 我们还比较了 9 月上述 3 个地区生长的红海榄, 却发现三者之间十分接近, 差异小于 $1 \%$, 且差异不 
显著 $(p>0.795)$, 北海、东寨港和厦门红海榄的 $\delta{ }^{13} \mathrm{C}$ 分别为 $-27.3 \%$ 、 $-27.9 \%$ 和 $-28.1 \%$ 。这些结 果表明有些红树植物如秋茄 $\delta{ }^{13} \mathrm{C}$ 值受环境因子的 影响比较大, 而另一些红树植物如红海榄的 $\delta{ }^{13} \mathrm{C}$ 值受环境因子的影响较小。对于同一种植物在不同 地方具有显著不同的 $\delta{ }^{13} \mathrm{C}$ 值可能有多个影响因 素, 凡是影响到叶片表面气孔开关的因素都有可能 导致植物叶片 $\delta{ }^{13} \mathrm{C}$ 值的不同, 如一个地区的温度 以及海水中的盐度 ( Lin \& Sternberg, 1992)。但很显 然, 并不是所有在不同地区分布的植物, 其 $\delta{ }^{13} \mathrm{C}$ 值 都有如此显著的变化, 或者不同植物可能有相反的 变化趋势 (比较表 1 中的秋茄和红海榄)。因此, 植 物叶片的 $\delta{ }^{13} \mathrm{C}$ 值究竟主要受哪种或哪些因素影响 还有待进一步的研究。

3.2 同一地区红树科不同种类植物间水分利用效 率的差异

根据 Ball(1988) 的研究, 桐花树 (Aegiceras corniculatum ) 的水分利用效率随着盐度增加和湿度的降 低而降低。但 Ball 同时也发现, 并不是每一个红树 植物都有相似的反映, 如白骨壤的水分利用效率并 不随着盐度的变化而变化。但两者都会因为盐度的 增加而导致生长速率的降低。Winter 等( 1982) 发 现, 禾本科㯟属植物 Panicum milioides 在环境从低的 相对湿度向高的相对湿度变化时, 其 $\delta{ }^{13} \mathrm{C}$ 值可能 增加 $2.7 \%$ 。同一个地区生长的植物当然会因为种 类的不同而导致显著的差异 (Guehl et al., 1998; Bonal et al., 2000), 如荫生植物和阳生植物, 这与它 们所固有的水分利用效率有关, 但同时也会因为在 群落中生长位置的局部小气候的差异而产生差异, 如生长高度 (Martinelli et al., 1998; Buchmann et $a l ., 1997$ )、距离破碎化生境的边缘程度 (Bonal et $a l ., 2000$ )、灌层的盖度 (Buchmann et al., 1997)、不 同的生活类型(如乔木、灌木、草本植物以及常绿和 落叶植物之间)(Brooks et al., 1997)。

从本研究的结果也可以看出, 同一地区生长的 不同种类红树植物, 其 $\delta{ }^{13} \mathrm{C}$ 值及其所放映的水分 利用效率也存在显著的差异, 但并不是所有种类之 间的差异都显著。虽然 5 月和 9 月北海生长的秋茄 和红海榄生长地都十分接近, 都是在较高潮位采集 的样品, 但 5 月秋茄的水分利用效率显著高于红海 榄的, 两者 $\delta{ }^{13} \mathrm{C}$ 值的差异接近 $2 \%$; 而 9 月两者 $\delta{ }^{13} \mathrm{C}$ 值的差异则仅为 $0.4 \%$; 5 月厦门采集的木榄和 秋茄的水分利用效率差异不显著, 而 9 月采集的红 海榄水分利用效率显著高于木榄和秋茄的, 但木榄
和秋茄之间差异不显著。

海南东寨港采集的红树种类较多, 故情形稍显 复杂。 5 月, 海南采集的 6 种红树植物基本可以分 成两组, 第一组包括海莲、红海榄、红树和木榄, 它们 具有比较高的水分利用效率。第二组包括角果木和 秋茄, 其水分利用效率显著低于第一组的。两个组 组内植物之间差异均不显著。9 月海南采集的红树 种类根据它们的 $\delta{ }^{13} \mathrm{C}$ 值也可以显著分成两组。第 一组包括角果木、红海榄、红树和秋茄, 他们具有相 对较高的水分利用效率; 第二组包括木榄和海莲, 他 们的水分利用效率显著低于第一组各植物种类。同 样, 两组植物组内各种类之间 $\delta^{13} \mathrm{C}$ 值的差异也不 显著。尽管两次采样的 6 种红树植物都可以分成两 组, 且两个组组成种类的数量一致, 较高水分利用效 率的组均有 4 种红树植物, 但组成种类前后有较大 的差异, 表现为 5 月采样的海莲和木榄与角果木和 秋茄相比, 具有相对较高的水分利用效率, 而 9 月的 采样则刚好相反, 即海莲和木榄的水分利用效率显 著低于角果木和秋茄的。不过, 红海榄和红树在 5 月和 9 月均有相对较高的水分利用效率(表 2)。

生长在云南的 3 种竹节树族的红树科植物除了 在 5 月竹节树与山红树和锯叶竹节树有显著差异, 其余均差异不显著, 表明这 3 种植物在对环境适应 上一定程度的趋同性。

3.3 海水与淡水中生长的红树科植物间水分利用 效率的差异

无论是 5 月, 还是 9 月的采样, 生长在云南陆地 淡水生境中的 3 种竹节树族红树科植物, 与生长在 海边盐水生境中的红树族红树科植物相比, 具有显 著较低的水分利用效率 $(p=0.000)$ 。其中, 在 5 月 具有最低 $\delta{ }^{13} \mathrm{C}$ 值的山红树要比北海的秋茄低 $6.8 \%$; 而在 9 月, 具有最低 $\delta{ }^{13} \mathrm{C}$ 值的竹节树也要比 北海的秋茄低 $5.6 \%$ 。

限制红树植物生长的一些环境因子主要包括海 水的盐度、土壤中 $\mathrm{N}$ 的水平、硫化物的含量和排水 能力。有研究指出, 高的盐度不仅减少叶片的气体 交换, 从而降低植物的生长, 而且还显著降低叶片对 C 同位素的甄别率, 或者增加蒸腾效率 (Lin \& Sternberg, 1992), 而其它因子则并没有显著的影响。以前 的研究还表明, 高的盐度能够降低气孔的张开, 引起 胞间 $\mathrm{CO}_{2}$ 浓度的降低, 从而导致低的对 $\mathrm{C}$ 同位素的 甄别和高的蒸腾效率 (Ball \& Farquhar, 1984)。同时, 前人的研究还观察到叶片对 C 同位素的甄别与胞 间 $\mathrm{CO}_{2}$ 浓度, 以及植物固有的蒸腾效率, 证实了叶片 
表 2 采自海南的红树科不同种类的植物 $\delta{ }^{13} \mathrm{C}$ 值比较

Table 2 Comparison in the mean foliar $\delta{ }^{13} \mathrm{C}$ values between plant species of the Rhizophoraceae family at the site of Dongzhai, Hainan

\begin{tabular}{|c|c|c|c|c|c|c|c|c|c|c|c|}
\hline 5 月 May & $\begin{array}{c}\text { 秋茄 } \\
\text { Kandelia } \\
\text { candel }\end{array}$ & $\begin{array}{c}\text { 角果木 } \\
\text { Ceriops } \\
\text { tagal }\end{array}$ & $\begin{array}{c}\text { 木榄 } \\
\text { Bruguiera } \\
\text { gymnorrhiza }\end{array}$ & $\begin{array}{c}\text { 红树 } \\
\text { Rhizophora } \\
\text { apiculata }\end{array}$ & $\begin{array}{c}\text { 红海榄 } \\
\text { Rhizophora } \\
\text { stylosa }\end{array}$ & 9 月 September & $\begin{array}{c}\text { 海莲 } \\
\text { Bruguiera } \\
\text { sexangula }\end{array}$ & $\begin{array}{c}\text { 木榄 } \\
\text { Bruguiera } \\
\text { gymnorrhiza }\end{array}$ & $\begin{array}{c}\text { 秋茄 } \\
\text { Kandelia } \\
\text { candel }\end{array}$ & $\begin{array}{c}\text { 红树 } \\
\text { Rhizophora } \\
\text { apiculata }\end{array}$ & $\begin{array}{c}\text { 红海榄 } \\
\text { Rhizophora } \\
\text { stylosa }\end{array}$ \\
\hline 角果木 (CTH) & ns & & & & & 木榄（BGH） & ns & & & & \\
\hline 木榄（BGH） & * & ns & & & & 秋茄（KCH） & * & $*$ & & & \\
\hline 红树（RAH） & * & * & ns & & & 红树 (RAH) & * & * & ns & & \\
\hline 红海榄（RSH） & * & * & ns & ns & & 红海榄（RSH） & * & * & ns & ns & \\
\hline 海莲（BSH） & * & * & ns & ns & ns & 角果木 (CTH) & * & * & ns & ns & ns \\
\hline
\end{tabular}

对 $\mathrm{C}$ 同位素甄别的变化主要是由胞间 $\mathrm{CO}_{2}$ 浓度的 变异造成的, 从而可以作为长期蒸滕效率的一个指 示 (Lin \& Sternberg, 1992)。

陆地生长的红树科植物 (竹节树族)的水分利用 效率与海水中生长的红树科植物 (红树族) 相比, 更 加接近于同一地区生长的非红树科植物 (渠春梅等, 2001）。说明竹节树族的红树科植物尽管仍保留了 一些红树族植物的形态特征 (如气生根), 但在水分 利用效率等生理生态特征上已经远离红树族植物的 特征，而趋向于与同一地区分布的其它热带植物 （Martinelli et al.，1998; 渠春梅等, 2001)。根据 Shi 等(2002)对红树科植物系统发生关系的研究, 内陆 生长的竹节树属和山红树属在遗传关系上较为接 近, 而海水中生长的红树属、木榄属、角果木属以及 秋茄属间的关系则更为紧密。但是, 是否这就是竹 节树族和红树族两者叶片之间 $\delta{ }^{13} \mathrm{C}$ 值显著差异的 根本原因,或者仅仅是因为两者处于不同的水分环 境的原因造成？对于这个问题,还需要做更多的实 验生态学的研究,例如比较不同水分环境中同一植 物 $\delta{ }^{13} \mathrm{C}$ 值以及其它生理生态学和形态学特征的差 异。不过, 从 Handley 等(1994)对大麦的研究表明, 以 $\delta{ }^{13} \mathrm{C}$ 值表示的水分利用效率大小的确有一定的 遗传学基础。他们认为, 大麦的水分利用效率是由 第四染色体控制的。另外，根据 Comstock 和 Ehleringer (1992)对美国西部沙漠中生长的一种灌木 植物 (Hymenoclea salsola) 的水分利用效率的研究也 发现, 即使在很大的温度和水分梯度下, 植物也有较 强的能力控制其水分利用效率。这足以证明 $\delta{ }^{13} \mathrm{C}$ 值所反映的水分利用效率确有一定的遗传学基础, 但必须也同时承认，植物水分利用效率的变化在很 大程度上也会受生长环境中环境因子变化的影响。

\section{参 考 文 献}

Ball MC, Farquhar GD (1984). Photosynthetic and stomatal re- sponses of two mangrove species, Aegiceras corniculatum and Avicennia marina, to long term salinity and humidity conditions. Plant Physiology, 74, $1-6$.

Ball MC (1988). Salinity tolerance in the mangroves Aegiveras corniculaturm and Avicennia marina. I. Water use in relation to growth, carbon partitioning, and salt balance. Australian Journal of Plant Physiology, 15, 447 - 464 .

Bonal D, Sabatier D, Montpied P, Tremeaux D, Guehl JM (2000). Interspecific variability of $\delta{ }^{13} \mathrm{C}$ among trees in rainforests of French Guiana: functional groups and canopy integration. Oecologia, 124, 454-468.

Björkman O, Demmig B, Andrews TJ (1988). Mangrove photosynthesis: response to high-irradiance stress. Australian Journal of Plant Physiology, 15, $43-61$.

Brooks JR, Flanagan LB, Buchmann N, Ehleringer JR (1997). Carbon isotope composition of boreal plants: functional grouping of life forms. Oecologia, 110, $301-311$.

Buchmannn N, Kao WY, Ehleringer J (1997). Influence of stand structure on carbon-13 of vegetation, soils, and canopy air within deciduous and evergreen forests in Utah, United States. Oecologia, $110,109-119$.

Chen SP (陈世苹), Bai YF (白永飞), Han XG (韩兴国) (2002) . Application of stable carbon isotope techniques to ecological research. Acta Phytoecologica Sinica (植物生态学报), 26, 549 - 560. (in Chinese with English abstract)

Clough BF, Sim RG (1989). Changes in gas exchange characteristics and water use efficiency of mangroves in response to salinity and vapour pressure deficit. Oecologia, 79, 38-44.

Comstock JP, Ehleringer JR (1992) . Correlating genetic variation in carbon isotopic composition with complex climatic gradients. Proceedings of the National Academy of Sciences of the United States of America, 89, 7747 - 7751.

Ehleringer JR, Field CB, Lin Z, Kuo C (1986). Leaf carbon isotope and mineral composition in subtropical plants along an irradiance cline. Oecologia, 70, 520-526.

Ehleringer JR, Lin ZF, Field CB, Sun GC, Kuo CY (1987) . Leaf carbon isotope ratios of plants from a subtropical monsoon forest. Oecologia, 72, $109-114$.

Fan HQ (范航清) (2001). Mangroves: the Coast Guard for the Environment (红树林一一海岸环保卫士). Guangxi Science and Technology Press, Nanning, 19. (in Chinese)

Farquhar GD, Ehleringer JR, Hubick KT (1989). Carbon isotope discrimination and photosynthesis. Annual Review of Plant 
Physiology and Plant Molecular Biology, 40, 503-537.

Gao YZ (高蕴璋) (1983). Rhizophoracea. In: Editoral Committee of Flora Peipublicae Populanis Sinicae, Chinese Academy of Sciences (中国科学院中国植物志编辑委员会) ed. Flora Reipublicae Popularis Sinicae (中国植物志), 52(2), 125 143. (in Chinese)

Glenn EP, Brown JJ, Khan MJ (1997). Mechanisms of salt tolerance in higher plants. In: Basra AS, Basra R eds. Mechanisms of Environmental Stress Resistance in Plants. Hardwood Academic Publishers, Australia, 83-110.

Guehl JM, Domenach AM, Bereau M, Barigah TS, Casabianca H, Ferhi A, Garbaye J (1998) . Functional diversity in an Amazonian rainforest of French Guyana: a dual isotope approach $\left(\delta{ }^{15} \mathrm{~N}\right.$ and $\delta{ }^{13} \mathrm{C}$ ). Oecologia, 116, 316-330.

Handley LL, Nevo E, Raven JA, Martinez-Carrasco R, Scrimgeour CM, Pakniyat H, Forster BP (1994). Chromosome 4 controls potential water use efficiency. Journal of Experimental Botany, $45,1661-1663$.

Hogarth PJ (1999). The Biology of Mangroves. Oxford University Press, Oxford.

Huc R, Ferhi A, Guehl JM (1994). Pioneer and late stage tropical rainforest tree species (French Guiana) growing under common conditions differ in leaf gas exchange regulation, carbon isotope discrimination and leaf water potential. Oecologia, 99, 297 305 .

Kao WY, Chang KW (1998). Stable carbon isotope ratio and nutrient contents of the Kandelia candel mangrove populations of different growth forms. Botanical Bulletin of Academia Sinica, 39, $39-45$.

Liang SC (梁士楚) (2001). Distribution pattern of Avicennia marina population on the sand beach of Beihai, Guangxi. Guangxi Sciences (广西科学) , 8(1), 57-60, 69. (in Chinese with English abstract)

Lin G, Sternberg L da SL (1992). Effect of growth form, salinity, nutrient and sulfide on photosynthesis, carbon isotope discrimination and growth of red mangrove (Rhizophora mangle L.). Australian Journal of Plant Physiology, 19, 509- 517.

Lloyd J, Farquhar GD (1994) . ${ }^{13} \mathrm{C}$ discrimination during $\mathrm{CO}_{2}$ assimilation by the terrestrial biosphere. Oecologia, 99, 201 215 .

Martinelli LA, Almeida S, Brown IF, Moreira MZ, Victoria BL, Sternberg LSL, Ferreira CAC, Thomas WW (1998). Stable car- bon isotope ratio of tree leaves, boles and fine litter in a tropical forest in Rondonia, Brazil. Oecologia, 114, $170-179$.

O'Leary MH (1981). Carbon isotope fractionation in plants. Phytochemistry, 20, $553-567$.

Qin HN (覃海宁) (2001). Rhizophoraceae. In: Fu LG (傅立 国), Chen TQ (陈谭清), Lang KY (郎楷永), Hong T (洪 涛), Lin Q (林祈), Li R (李容) eds. Higher Plants of China Vol. 7 (中国高等植物・第 7 卷). Qingdao Publishing House, Qingdao, 675-682.

Qu CM (渠春梅), Han XG (韩兴国), Su B (苏波), Huang JH (黄建辉), Jiang GM (蒋高明) (2001). Edge effects of plant water use efficiency indicated by folia $\delta{ }^{13} \mathrm{C}$ value in a fragmented seasonal rainforests in Xishuangbanna. Acta Phytoecologica Sinica (植物生态学报), 25, 1-5. (in Chinese with English abstract)

Shi S, Zhong Y, Huang Y, Du Y, Qiu X, Chang H (2002). Phylogenetic relationships of the Rhizophoraceae in China based on sequences of the chloroplast gene $m a t K$ and the internal transcribed spacer regions of nuclear ribosomal DNA and combined data set. Biochemical Systematics and Ecology, 30, 309-319.

Tang JW (唐建维), Zhang JH (张建候), Song QS (宋启示), Huang ZY (黄自云), Li ZN (李自能), Wang LF (王利繁), Zeng R (曾荣) (2003). Biomass and net primary productivity of artificial tropical rainforest in Xishuangbanna. Chinese Journal of Applied Ecology (应用生态学报), 14, 1-6. (in Chinese with English abstract)

Winter K, Holtum AM, Edwards GE, O'Leary MH (1982). Effect of low relative humidity on $\delta{ }^{13} \mathrm{C}$ value in two $\mathrm{C}_{3}$ grasses and in Panicum milioides, a $\mathrm{C}_{3}-\mathrm{C}_{4}$ intermediate species. Journal of Experimental Botany, 33, 88-91.

Ye Y (叶勇), Lu CY (卢昌义), Tam N (谭凤仪), Wong Y (黄玉山), Lin P (林鹏) (2000). Rate of methane production from the wetland of mangrove forest and the effect of soil physical and chemical factors on it. Acta Pedologica Sinica (土壤学报), 37, 77 - 84. (in Chinese with English abstract)

Zhao KF (赵可夫), Feng LT (冯立田), Lu YF (卢元芳), Fan H (范海) (1999). The osmotica and their contributions to the osmotic adjustment for Kandelia candel (L.) Druce and Avicennia marina (Forsk) Vierh growing in the Jiulongjiang River estuary. Oceanologia et Limnologia Sinica (海洋与湖沼), 30, 58 - 61. (in Chinese with English abstract) 